\title{
Adolescent Girls with Pure Gonadal Dysgenesis: A Rare Disease
}

\author{
J SAHA $^{\mathrm{a}}, \mathrm{K}^{\text {BEGUM }}{ }^{\mathrm{b}}, \mathrm{KA} \mathrm{KHANOM}^{\mathrm{c}}$, I PRASAD $^{\mathrm{d}}, \mathrm{S}$ AKTER $^{\mathrm{e}}$
}

Summary:

Gonadal dysgenesis is a rare cause of primary amenorrhoea, which is a relatively common problem among teenage girls.Primary amenorrhoea occurs in patient with gonadal dysgenesis because of absence or limited ovarian function due to inappropriate development.Streak gonads are unable to produce estrogens and/or androgens,resulting in minimal to no development of secondary sexual characteristics.Adrenal androgens may induce production of pubic hair,but patient will have minimal breast development.These patients may have a family history of infertility, short stature,sensorineural deafness,ataxia,mild mental retardation or gonadoblastoma.

Here two cases of primary amenorrhoea due to pure gonadal dysgenesis are presented. $1^{\text {st }}$ one was a $18 y$ r old girl whose mother consulted with a gynaecologist at the age of 16yr because of her worries about absence of menarche of her daughter and secondone was a 14yr old girl whose mother consulted with a gynaecologist at the

Introduction:

Gonadal dysgenesis may be defined as any congenital developmental disorder of the reproductive system $^{5}$ characterized by a progressive loss of germ cells on the developing gonads ofan embryo. ${ }^{6}$ This loss leads to extremely hypoplastic (underdeveloped) and dysfunctioning gonads mainly composed of fibrous tissue, hence the name streak gonads. Gonadal dysgenesis is frequently associated with whole or partial deletion of the $\mathrm{X}$ chromosome.Thus, Turner

a. Dr. Joysree Saha, Assistant Professor, Department of Gynae \& Obs,Popular Medical College, Dhaka.

b. Dr. Kohinoor Begum, Professor and Head, Department of Gynae \& Obs, Popular Medical College, Dhaka.

c. Dr. Kamil Ara Khanom Associate Professor, Department of Gynae \& Obs, Popular Medical College, Dhaka.

d. Dr. Indrajit Prasad, Associate Professor, Department of Endocrinology, Dhaka Medical College, Dhaka.

e. Dr. Sumaya Akter, Registrar, Department of Gynae \& Obs, Popular Medical College, Dhaka.

Address of Correspondence: Dr. Joysree Saha, Assistant Professor, Department of Gynae \& Obs, Popular Medical College, Dhaka.

Received: 18 September, 2017

Accepted: 14 June 2018 age of 16yr because of absence of secondary sexual characteristics as well as menarche of her daughter.

In both cases, blood test showed very high levels of follicle stimulating hormone (FSH) \& luteinizing hormone (LH), low levels of oestradiold very low level of AMH. USG findings of both cases showed a bit hypoplastic uterus and volume of ovaries were smaller than normal. A diagnostic laparoscopy with biopsy of both gonads of one case was performed.Another case did not give consent for laparoscopy.Hormonal replacement therapy was applied on them for establishment of normal menstruation and menstruation was established in both cases.

An early diagnosis is extremely important to prevent long term consequences of Gonadal dysgenesis.

Key word: Primary Amenorrhoea, Gonadal dysgenesis.

(J Bangladesh Coll Phys Surg 2018; 36: 170-174) DOI: http://dx.doi.org/10.3329/jbcps.v36i4.38187

syndrome $(45, \mathrm{XO})$ is responsible for $50 \%$ of gonadal dysgenesis,mosaics $(46, \mathrm{XY} / 45, \mathrm{XO})$ represent $25 \%$ of cases, Pure gonadal dysgenesis (46 XX) and Swyer syndrome (46XY) the other $25 \%{ }^{7}$

Gonadal dysgenesis without the phenotype of Turner syndrome is described as 'Pure'.Pure Gonadal dysgenesisis characterized by female external phenotype and internal duct structure. It is often presented withPrimary amenorrhoea with or without normal secondary sex characteristicssuch as breast development. ${ }^{8}$ With non functional streak ovaries, patient has low estrogen levels (hypoestrogenic) and has high levels of FSH and LH. Estrogen and progesterone therapy is usually then commenced. ${ }^{4}$ This is autosomal recessive trait,so genetic counseling is warranted. The gonads usually do not carry risk of malignant degeneration.

A normal menstrual cycle requires a complex interaction between the ovary, pituitary gland, hypothalamus axis and the genitalias. Any alteration in such interaction could cause amenorrhoea. 
Primary amenorrhoea is diagnosed in women with normal secondary sexual characteristics but who have not menstruated by age of 16 years ${ }^{1,2}$ or without normal secondary sexual characteristics as well as non establishment of menarche by age of 14 years. Secondary amenorrhoea is the absence of menses for 3 months in women with previously normal menstruation and for 9 months in women with previous oligomenorrhoea. According to previous investigations, secondary amenorrhea is more common than primary type but a very rare presentation of gonadal dysgenesis. 3,4

In this paper, we present two teenage girls who failed to start menarche. We analyze the diagnostic process and discuss the causes and treatment for this medical condition.

\section{Case-1:}

A 18 years old girl was consulted with her doctor for a typical case of primary amenorrhoea.Regarding family history her mother had menarche at 11 years of age.

The patient's personal medical record did not include any serious illness, and secondary sexual characteristics developed by age of 12 . She didn't present signs of hearing loss or deafness.

A physical examination revealed the following data: $1.4 \mathrm{~m}$ height, $52 \mathrm{~kg}$ weight and body mass index (BMI) $22.97 \mathrm{Kg} / \mathrm{m}^{2}$. She presented withnormal axillary and pubic hair development and a small mammary development. Her external genitalias werenormal and her clitoris was of normal size.

\section{Investigations:}

Two different blood analyses showed a normal haemogram and biochemistry, elevated levels of follicle stimulating hormone (FSH) and luteinizing hormone (LH) and low levels of oestradiol.

In October 2013 values were:

FSH - $106.71 \mathrm{mU} / \mathrm{ml}, \mathrm{LH}-38.69 \mathrm{mU} / \mathrm{ml}$, oestrogen level $-33.2 \mathrm{pg} / \mathrm{ml}$ and thyroid stimulating hormone (TSH) $-2.92 \mu \mathrm{U} / \mathrm{ml}$. Prolactin level was $13.1 \mathrm{ng} / \mathrm{ml}$, Anti mullerian hormone (AMH) $-0.02 \mathrm{ng} / \mathrm{ml}$ which is very low.

\section{In November 2015 values were:}

FSH $-78 \mathrm{mU} / \mathrm{ml}, \mathrm{LH}-42.63 \mathrm{mU} / \mathrm{ml}$, oestrogen level $-16.38 \mathrm{pg} / \mathrm{ml}$
Prolactin level was $19.9 \mathrm{ng} / \mathrm{ml}$, Serum cortisol - 136.0 $\mathrm{ng} / \mathrm{ml}$ (normal range).Abdominal ultrasound (12.09.2013) revealed uterus smaller than normal size with thin endometrium. Both ovarian volume are smaller than normal with very few follicles.(volume of right ovary was $2.5 \mathrm{cc} \&$ left was $3.5 \mathrm{cc}$ ).

Her peripheral blood karyotype was done on 28.10 .13 showing normal karyotype (46 XX) which eliminated any possibility of mosaicis. (Picture of Karyogram attached)

An x-ray of the carpus was taken for determining her bone age, which was in agreement with her chronological age.

A diagnostic laparoscopy was performed with the following results: Hypoplastic uterus with normal fallopian tubes; small size ovaries with smooth surfaces and lack of ovulatory stigmas. A biopsy of both gonads was performed.

The pathological report showed a thinned cortex in both ovaries with a fibrous looking stroma. The number of primary follicles was very low for the patient's age, with a total absence of corpus luteum. The morphological findings were compatible with a gonadal dysgenesis.

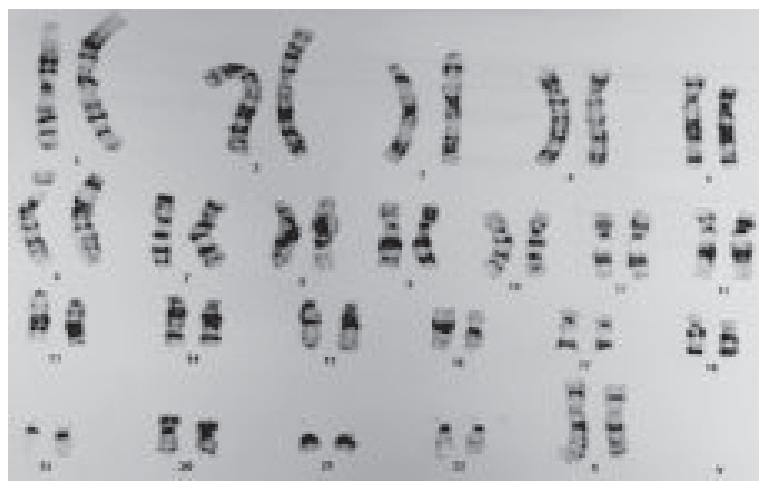

Fig.-1: Karyogram (Case 1)

\section{Case-2:}

A 15 years old girl was consulted with her gynaecologist for non establishmentof menstruation. Regarding family history her mother had menarche at 12 years of age.

Other siblings of her had no history of primary amenorrhoea or delayed puberty and had normal stature with other secondary sexual characteristics. 
She had no significant previous medical or surgical history upto age of 15 years. She didn't present any sign of hearing loss or deafness or any visual disturbance.

On physical exam: Height $-1.2 \mathrm{~m}$, weight $-40 \mathrm{~kg}$ and a BMI $-23.15 \mathrm{Kg} / \mathrm{m}^{2}$. She presented with incomplete axillary \& pubic hair development and a little bit small mammary development. Her external genitalias were normal \& her clitoris was of normal size.

Investigations: Her blood analyses also showed the same findings like first case - elevated levels of follicle stimulating hormone (FSH) and luteinizing hormone (LH) and low levels of oestradiol.

\section{In December 2013 values are:}

FSH $-86.70 \mathrm{mIU} / \mathrm{ml}, \mathrm{LH}-30.20 \mathrm{mIU} / \mathrm{ml}$, oestradiol level $-2.72 \mathrm{pg} / \mathrm{ml}$.

\section{In January 2016 values are:}

FSH - $72.20 \mathrm{mIU} / \mathrm{ml}$, LH - $35.20 \mathrm{mIU} / \mathrm{ml}$, Serum Prolactin level was $26.30 \mathrm{ng} / \mathrm{ml}$, TSH $-1.44 \mathrm{UIU} / \mathrm{ml}$, AMH $-<0.01 \mathrm{ng} / \mathrm{ml}$

An abdominal ultrasound (14.12.13) revealed a small structure about $2.2 \times 1.5 \times 0.8 \mathrm{~cm}$ simulating a uterus behind the urinary bladder. Ovaries could not be visualized.

Repeat USG of abdominal organs done on 03.01.16 showed small size uterus $(40 \times 8 \mathrm{~mm})$ than normal. Both ovaries are also small in size (right $-11 \times 8 \mathrm{~mm}$ \& left $-11 \times 7 \mathrm{~mm}$ ).

Her peripheral blood karyotype was done on 24.12.13 revealed normal karyotype (46 XX) which eliminated any possibility of mosaicisms. (Picture attached)

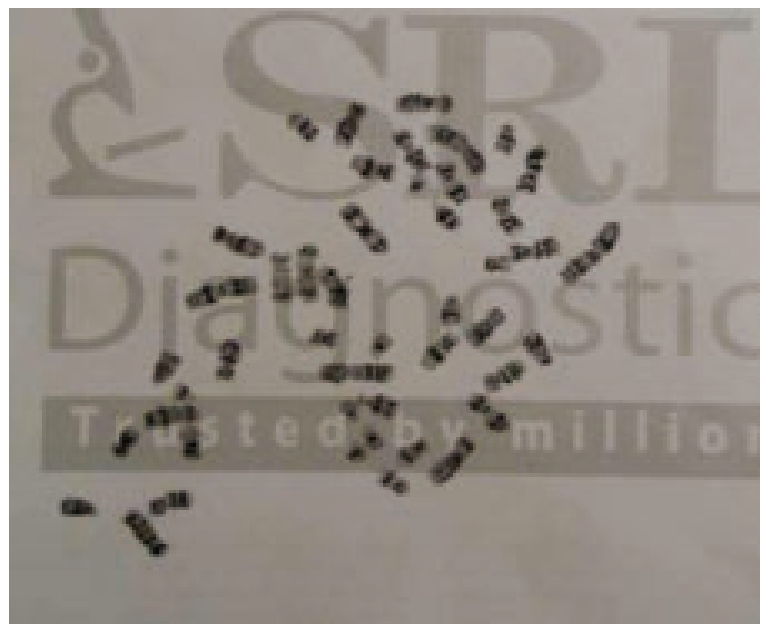

Fig.-2: Karyogram (case 2)
Her x-ray of hands was done to determine bone age which was corresponded with her chronological age.

As AMH gives an authentic picture of ovarian reserve of follicles, it can be a substitute for ovarian biopsy, if the patient do not want to have it. In this case AMH is very low representing the very low reserve of ovarian follicles.

\section{Discussion:}

In our daily practice most primary amenorrhoea cases, we found were cases of Turner syndrome, some are mosaicisms or XY karyotype (Swyer syndrome) or Testicular Feminization Syndrome. Very few were confirmed cases of pure gonadal dysgenesis $(46 \mathrm{XX}) .{ }^{12}$

Gonadal dysgenesis includes - pure gonadal dysgenesis (46 XX or $46 \mathrm{XY}=$ Swyer syndrome; bilateral streak gonads), mixed gonadal dysgenesis (e.g. mosaicism $45 \mathrm{X} 0 / 46 \mathrm{XY}$; differentiated testicles or ovaries on one side and a streak gonad on the other side) and the Turner syndrome. ${ }^{7}$ The condition may be due to Perrault Syndrome (XX gonadal dysgenesis + sensorineural hearing loss) or exposure to environmental endocrine disruptors. Another type of $\mathrm{XX}$ gonadal dysgenesis is known as $46, \mathrm{XX}$ gonadal dysgenesis epibulbardermoid, which follows the similar symptoms as the regular syndrome, though it also shows signs of epibulbardermoid (eye disorder). ${ }^{9,10,11}$ It has been suggested to be a new type of syndrome. ${ }^{9}$

Pure gonadal dysgenesis generally are seen at puberty with primary amenorrhoea. ${ }^{19}$ Our two reported cases also presented with primary amenorrhoea.

Nazareth et al.described consistent results in four 46,XX siblings affected by pure gonadal dysgenesis syndrome. They belived that inheritance of gene in these cases was autosomal recessive and limited to female sex. ${ }^{12}$ Furthermore, Namavar-Jahromiet al.presented three sisters with 46,XX pure gonadal dysgenesis, whowere born from a first cousin marriage. ${ }^{18}$ Our two reported cases had no significant family histoy like this.

These patients may present with short stature. ${ }^{20}$ our reported cases presented with BMI-22.97 and 23.15, which mimicks with usual presentation of gonadal dysgenesis. 
Most authors agree on the fact that gonadal dysgenesis does not cause breast development due to low levels of circulating oestradiol. Nevertheless, the development of pubic and axillary hair could be normal due to a normal production of androgens by the suprarenal gland.

Stenchever considers the fact that patients with pure gonadal dysgenesis or mosaicism could have few ovarian follicles during early puberty and the same time produce enough oestrogen for the development of mammary glands. ${ }^{13} \mathrm{We}$ would like to stress the fact that our patient showed breast development, but it was incomplete.

FSH,LH levels are generally elevated and Estrogen ,Testosterone levels are decreased in pure gonadal dysgenesis. ${ }^{19} \mathrm{We}$ also found FSH-106.71mu/ $\mathrm{mi}, 86.70 \mathrm{mu} / \mathrm{ml}$ and $\mathrm{LH}-38.69 \mathrm{mu} / \mathrm{ml}, 30.20 \mathrm{mu} / \mathrm{ml}$ in our patients which corresponds to the findings of pure gonadal dysgenesis.Level of oestrogen in our patients was $33.2 \mathrm{pg} / \mathrm{ml}, 38.52 \mathrm{pg} / \mathrm{ml}$. This value was the minimum level of normal which might be the cause of her incompietebreast development, as well as her attended physician prescribed hormone, at that time for the establishment of menstruation.

In these patients it is recommended to perform routine screening to eliminate hypothyroidism, and in cases where symptoms appear, to eliminate other endocrine disorders. ${ }^{14}$ Our patients had normal TSH levels and did not show any sign of hypothyroidism.

As AMHgives an authentic picture of ovarian reserve of follicles, it can be a substitute for ovarian biopsy if the patient does not want to have it. In our cases $\mathrm{AMH}$ is very low representing the very low reserve of ovarian follicles.

The most common probable cause for primary ovarian failure is autoimmunity. These patients also have a higher risk of developing other immunological disorders such as Hashimoto thyroiditis, hypoparathyroidism, adrenal insufficiency or pernicious anaemia. We did not investigate for her anti-thyroid, anti-ovarian or anti-adrenal antibodies, so we cannot rule out an autoimmune etiology.

In the reported case- 1: USG in 2013 showed small sized ovaries with presence of few follicles .In case2: USG in 2016 showed small sized ovaries. Thesepresentation are comparable with findings of pure gonadal dysgenesis.
Nowadays, genetic assessment is recommended, especially in the case of families with fragile $\mathrm{X}$ syndrome. If an isolated case occurs, the risk to other women in the family of developing this illness is probably the same as for the rest of the population.Peripheral blood karyotype of both of our patients was $46, \mathrm{XX}$.

Ropke et al consider mosaicism in gonadal karyotype as a frequent cause of gonadal dysgenesis, regardless of a normal peripheral karyotype. ${ }^{15}$ They strongly recommended testing the karyotype of the gonadal tissue because this information could be extremely useful.

In addition, Massin et al recommend an ovarian biopsy in case of pure gonadal dysgenesis due to the fact that, it is a stronger indicator than pelvic ultrasound for the presence of follicles in the ovaries. ${ }^{16}$ Our first case underwent a diagnostic laparoscopy with ovarian biopsy that confirmed our diagnostic hypothesis (fig 1). Second case was not agreed to undergo laparoscopy. We did not do karyotyping of the gonadal tissue, can be considered as a limitation in this study.

Long-term lack of oestrogen could cause early bone loss and osteoporosis in these patients. In addition, the lack of female sexual hormones represents an important risk factor for neurological, metabolic and cardiovascular health problems. Therefore, these patients would require hormone replacement therapy with oestrogens and progesterone. ${ }^{17}$ So we prescribe their treatment and after giving treatment of six to nine months they start menstruation.our findings correlate with the findings of Baron J. et al. ${ }^{21}$

The aim of giving treatment is to prevent sterility and tumorigenesis.Sterility is an obvious consequence in patients with premature ovarian failure. Nevertheless, patients could become mothers with proper endometrial stimulation and subsequent implanting of embryos, fertilized with donated ovum. ${ }^{22}$

Furthermore, Namavar-Jahromi et al. obtained that malignant degeneration of the streak gonads should be considered in the patients with 46, XX PGD. ${ }^{18}$ Usually tumorigenesis occurs in patients with identifiable $\mathrm{Y}$ chromosome, however malignant degeneration of the streak gonads in the patients with $46, \mathrm{XX}$ pure gonadal dysgenesis can also be noted. 


\section{Conclusion:}

Any evaluation of a woman with primary amenorrhoea must begin with a detailed history, physical examination and careful review of her clinical background. If recommended, a series of blood analysis including female sexual hormones (oestrogens and progesterone) and levels of gonadotropins (follicle stimulating hormone (FSH) and luteinizing hormone $(\mathrm{LH})$ ) should be included.

An early diagnosis is extremely important in order to start treatment promptly for the management of symptoms, provide emotional support to the patient and reduce the risks of long term complications.

As gonads in above cases cannot make estrogen and progesterone, so HRT with OCP or sequential pill were given for withdrawl bleeding as well as for development of secondary sexual characteristics. This is often given through the skin now.

As gonads cannot produce eggs, they would not be able to conceive children naturally. A woman with a uterus but no ovaries may be able to become pregnant by implantation of another woman's fertilized egg (embryo transfer)-might be a solution for them.

Patient's consent:Patient/guardian consent was obtained for publication in both cases.

\section{References:}

1. Practice Committee of the American Society for Reproductive Medicine Current evaluation of amenorrhea. FertilSteril. 2004; 82(Suppl 1):S33-9. [PubMed]

2. Creatsas GK, Creatsas M. Frontiers in Gynecological Endocrinology. New York: Springer; 2014. Pathophysiology and clinical assessment of primary amenorrhea; pp. 3-7.

3. Speroff L, Fritz MA. Clinical gynecologic endocrinology and infertility. United States: Lippincott Williams and wilkins; 2005.

4. Master-Hunter T, Heiman DL.: Amenorrhoea: evaluation and treatment. Am Fam Physician 2006; 73: 1374-82 [PubMed]

5. Eberhard Nieschlag; Hermann M. Behre; Susan Nieschlag (July 2009). Andrology: Male Reproductive Health and Dysfunction. Springer. pp. 221-. ISBN 978-3-540-78354-1. Retrieved 10 November 2010.

6. M. Sperling (2008). Pediatric endocrinology. Elsevier Health Sciences. pp. 667-. ISBN 978-1-4160-4090-3. Retrieved 27 October2010.
7. Binta Leigh, Christoph Dorn, Uwe Ulrich. Gonadal dysgenesis, GynacolGeburtsmed, GynakolEndokrinol, 2009; 5(2): 82-94, ISSN $1614-8533$

8. Narayanan VK, Tolmie J, Donaldson M. 46, XX pure gonadal dysgenesis with tall stature due to an Xq21.2 deletion. 2013: $33-52$.

9. Quayle SA, Copeland KC (1991). 46,XX gonadal dysgenesis with epibulbardermoid. Am. J. Med. Genet. 40 (1): 75 6.doi:10.1002/ajmg.1320400114.PMID1909490.

10. 46,XX Gonadal dysgenesis epibulbardermoid at NIH's Office of Rare Diseases

11. ORPHANET - About rare diseases - About orphan drugs Archived January 13, 2005, at the Wayback Machine.

12. Gymez Marcos MA, Garcwa Ortiz L, Diego Robledo FJ, et al. C Published online 2009 Apr 14. Doi: 10.1136/bcr.07 .2008.0485

13. Stenchever MA. Primary amenorrhoea. Comprehensive gynecology. $4^{\text {th }}$ edn St Louis, Missouri, USA: Mosby Inc, 2001

14. Timmreck LS, Reindollar RH. Contemporary issues in primary amenorrhoea. ObstetGynecolClin N Am 2003; 30: 287-302 [PubMed]

15. Ropke A, Pelz A, Volleth M, et al. Sex chromosomal mosaicism in the gonads of patient with gonadal dysgenesis, but normal female or male karyotypes in lymphocytes. Am J ObstetGynecol 2004; 190: 1059-62 [PubMed]

16. Massin N, Czernichow C, Thibaud E, et al. Idiopathic premature ovarian failure in 63 young women. Horm Res 2006; 65: 89-95 [PubMed]

17. Rare disease $46 \mathrm{XX}$ pure gonadal dysgenesis: an infrequent cause of primary amenorrhoea Salvador Pertusa and Ana Palacios. BMJ Case Rep. 2009; 2009: bcr07 .2008.0485. Published online 2009 Apr 14. Doi: 10.1136/bcr.07 .2008.0485

18. Namavar-Jahromi B, Mohit M, Kumar PV. Familial dysgerminoma associated with 46, XX pure gonadal dysgenesis. Saudi Med J. 2005;26:872-4. [PubMed]

19. John M. Gatti MD, 2010.Disorders of sexual differentiation.in Ashcraft's pediatric surgery (Fifth Edition)

20. Alison Woodworth.Primary amenorrhoea due to Pure Gonadal Dysgenesis/ Agenesis.http://www.cancertherapyadvisor.com/ labmed/primary-amenorrhea-due-to-pure-gonadaldysgenesisagenesis/article/613642/

21. Baron J, Warenik-SzymankiewiczA, Miedzianowski J, Baron JJ. New aspects of diagnosing and treating pure gonadal dysgenesis 46XY and 46XX.Endokrynol Pol. 1993;44(4):483-96.

22. Salvador P, Ana P.46 XX pure gonadal dysgenesis: an infrequent cause of primary amenorrhoeaBMJ Case Rep. 2009; 2009: bcr07.2008.0485. 